\title{
Cerebral oxygenation responses during kangaroo care in low birth weight infants
}

\author{
Esmot Ara Begum*1, Motoki Bonno1, Noriko Ohtani², Shigeko Yamashita², \\ Shigeki Tanaka ${ }^{1}$, Hatsumi Yamamoto ${ }^{1}$, Masatoshi Kawai ${ }^{3}$ and \\ Yoshihiro Komada ${ }^{4}$
}

\begin{abstract}
Address: ${ }^{1}$ Clinical Research Institute and Department of Pediatrics, National Hospital Organization, Miechuo Medical Center, 2158-5 Hisaimyojin Cho, Tsu, Mie, 514-1101, Japan, ${ }^{2}$ Department of Nursing, National Hospital Organization, Miechuo Medical Center, 2158-5 Hisaimyojin Cho, Tsu, Mie, 514-1101, Japan, ${ }^{3}$ Masatoshi Kawai, PhD, Department of Developmental Clinical Psychological Institute for Education, Mukogawa Women's University, 6-46 Ikebiraki Cho, Nishinomiya, Hyogo, 633-8558, Japan and ${ }^{4}$ Department of Pediatrics and Developmental Science, Mie University Graduate School of Medicine, 174-2 Edobashi, Tsu, Mie, 514-8507, Japan

Email: Esmot Ara Begum* - esmotara@hotmail.com; Motoki Bonno - bonnomo@hotmail.com; Noriko Ohtani - noriko_03@hotmail.com; Shigeko Yamashita - ANB12432@nifty.com; Shigeki Tanaka - tanakash@miechuo-m.hosp.go.jp; Hatsumi Yamamoto - hatsumimi@umin.ac.jp; Masatoshi Kawai -m-kawai@r2.dion.ne.jp; Yoshihiro Komada-komada@clin.medic.mie-u.ac.jp

* Corresponding author
\end{abstract}

Published: 7 November 2008

BMC Pediatrics 2008, 8:5। doi:10.1|86/|47|-243|-8-5|

This article is available from: http://www.biomedcentral.com/|47|-243I/8/5 I

(C) 2008 Begum et al; licensee BioMed Central Ltd.

This is an Open Access article distributed under the terms of the Creative Commons Attribution License (http://creativecommons.org/licenses/by/2.0), which permits unrestricted use, distribution, and reproduction in any medium, provided the original work is properly cited.
Received: I August 2008

Accepted: 7 November 2008

\begin{abstract}
Background: Kangaroo care (KC) has been widely using to improve the care of low birth weight infants. However, very little is known about cerebral hemodynamics responses in low birth weight infants during $\mathrm{KC}$ intervention. The objective of this study was to elucidate the response of cerebral hemodynamics during $\mathrm{KC}$ in low birth weight infants.

Methods: Near infrared spectroscopy measured regional cerebral oxygenation $\left(\mathrm{rSO}_{2}\right)$, heart rate $(\mathrm{HR})$, respiration rate (RR) measured by electrocardiogram, and percentages of oxygen saturation $\left(\mathrm{SpO}_{2}\right)$ measured by pulse oxymetry was monitored in 16 preterm infants (< I600 g) in three sessions: before, during, and after KC. Using power spectral analysis, total power (TP), low-frequency (LF, 0.02-0.20 Hz) and high-frequency $(\mathrm{HF}, 0.20-0.50 \mathrm{~Hz})$ bands, the ratio of LF/HF were calculated and normalized as \%LF or $\% H F=L F$ or HF/TP $\times 100(\%)$.

Results: Significant differences were not observed in the mean $\mathrm{rSO}_{2}, \mathrm{HR}$, and $\mathrm{SpO}_{2}$ throughout sessions; however, the TP of these parameters was significantly decreased during $K C$ and increased after $K C$ ( $P<$ $0.001)$. The \% $\mathrm{LF}$ of $\mathrm{LrSO}_{2}$ and $\mathrm{RrSO}_{2}$ was decreased during $\mathrm{KC}(\mathrm{p}<0.05)$ with decreased \%HF in $\mathrm{RrSO}_{2}$ $(p<0.05)$. The \%LF of HR was significantly increased during $K C$ while \%HF was decreased $(p<0.05)$. Mean and TP of RR was increased during $K C(p<0.0$ I respectively) with the increase of quiet sleep state $(p<$ $0.05)$ and decreased after KC $(p<0.0 I)$. The \%LF of RR was increased after KC $(p<0.05)$ with decreased \%HF ( $P<0.05)$; however, significant changes were not observed during KC.

Conclusion: KC intervention appears to have influence on cerebral hemodynamics as well as cardiorespiratory parameters. The results of $\mathrm{rSO}_{2}$ and $\mathrm{HR}$ might be associated with quiet sleep states. The results of this study may indicate the contribution of $\mathrm{KC}$ intervention to the activation of central nervous system and brain function. Further study is needed to determine the underlying physiology responsible for these differences.
\end{abstract}




\section{Introduction}

Recently, skin - to - skin care, called kangaroo care (KC), has been widely practiced for preterm and low birth weight (LBW) infants in the neonatal intensive care unit (NICU). During kangaroo care, the mother holds a naked infant in a vertical position against the breasts so that the infant can achieve skin - to - skin contact. KC was first introduced in Bogotá, Columbia by Dr. Edgar Rey and Hector Martinez in 1978 as a way of compensation for the overcrowding of incubators in hospitals caring for preterm infants [1]. According to their report on $\mathrm{KC}$, they have found improved outcomes in survival rates and health status. Now, KC is practiced not only in developing countries, but also in developed countries.

Many studies have been performed to evaluate the psychological and physiological responses during $\mathrm{KC}$ in preterm infants [2-4]. Positive psychological effects on mothers and mother - infant bonding are well recognized [5]; however, the physiological effects of KC are still inconclusive. Previously, it has been reported that KC improves thermal regulation [6-8], respiratory pattern and oxygen saturation $[9,10]$, reduces apnea and bradycardia $[9,11]$, accelerates weight gain [12], increases vagal tone responses [13], reduces activity level, and enhances the duration of quiet sleep $[14,15]$ in preterm infants. On the other hand, increases in body temperature have been found to be associated with an increased frequency of apnea and bradycardia [16] and an increased oxygen requirement during $\mathrm{KC}$ was found in intubated infants [17]. Most of these studies were performed on cardiorespiratory parameters rather than cerebral hemodynamics. Preterm infants are highly susceptible to develop various cerebral lesions like intraventricular hemorrhage or periventricular leucomalacia following cerebral hypoperfusion because of their immature brain [18]. Cerebral oxygenation is one of the important parameters in cerebral hemodynamics, has been widely used to monitor cerebral perfusion in infants with birth asphyxia or brain lesions like hypoxic-ischemic encephalopathy [19-21]. The response of cerebral hemodynamics in accordance with sleep states was reported previously [22]; however, no study has yet been performed on the response of cerebral hemodynamics in preterm infants during KC intervention.

Spectral analysis of time series data using Fast Fourier transformation (FFT) has been widely utilized to study the autonomic nervous system [23-26]. In power spectral analysis, low - frequency region from $0.02-0.20 \mathrm{~Hz}$ is reflected sympathetic activities and high-frequency region from $0.2-2.0 \mathrm{~Hz}$ is reflected parasympathetic activities and total power, a index of total variance (the total area under the curve of power spectral density) and the ratio of LF/HF power reflects the balance between sympathetic and parasympathetic activities. Two studies have been reported on the heart rate variability (HRV) during KC using power spectral analysis $[27,28]$; however, their results were not conclusive. Further, previous studies on cerebral hemodynamics using power spectral analysis have reported the position dependent responses in adult [29], however, no study have been performed on the spectral characteristics of cerebral hemodynamics during KC position in preterm infants.

In this study, we investigated cerebral hemodynamics in addition to cardiorespiratory parameters in preterm infants during KC intervention using power spectral analysis. Therefore, we investigated regional cerebral oxygenation $\left(\mathrm{rSO}_{2}\right)$ as a parameter of cerebral hemodynamics, heart rate (HR), respiratory rate (RR), and $\mathrm{SpO}_{2}$ in stable low birth weight infants during $\mathrm{KC}$ using power spectral analysis.

\section{Materials and methods Subjects}

Nineteen preterm infants with birth body weight $<1,600$ $\mathrm{g}$ and gestational age $<33$ weeks (wks) were enrolled in this study. All of the infants were stable and breathed spontaneously without supplemental oxygenation with postconceptional age $\geq 32$ wks. Infants who had severe congenital malformations, severe asphyxia, and a potential cause of apnea other than immaturity, such as sepsis or intracranial hemorrhage, were excluded from the study. Three infants were excluded because of interrupted observation. Finally, 16 infants were selected for further analysis (Table 1). The median gestational age was $28 \mathrm{wks}$ (range, 24 - 33 wks) and median birth body weight was $1,228 \mathrm{~g}$ (range, $692-1,586 \mathrm{~g}$ ). Postconceptional age on the day of the study was 36 wks (range, $33-42$ wks) and body weight was $1,458 \mathrm{~g}$ (range, $946-1,858 \mathrm{~g}$ ). Eight infants were born via caesarean section. Seven infants had received mechanical ventilation after birth for a median duration of 6 days. Four infants had received theophylline for apnea on the day of KC intervention.

\section{$K C$ and data collection}

$\mathrm{KC}$ intervention was performed for one hour. The temperature of the room ranged from 27 to $28^{\circ} \mathrm{C}$ and the humidity ranged from 60 to $70 \%$ during KC. Infants were observed carefully and monitored in three conditions: 30 minutes in the incubators (before $\mathrm{KC}$ ), 1 hour of $\mathrm{KC}$ intervention (during $\mathrm{KC}$ ), and 30 minutes in the incubator again after $\mathrm{KC}$ intervention. Mothers were seated on a reclining chair at a $60^{\circ}$ angle, wearing a front opening blouse. The infants were placed naked except for a diaper directly onto the skin between the breasts and covered with a light blanket. Infants were fed 1 hour before KC. All infants were continuously monitored with electrocardiogram to determine HR, RR and with pulse oxymetry for 
Table I: Characteristics of 16 low birth weight infants participating in Kangaroo care

\begin{tabular}{|c|c|c|c|c|c|c|c|c|}
\hline \multirow[t]{2}{*}{ Subject number } & \multirow[t]{2}{*}{ Sex } & \multirow[t]{2}{*}{ GA (wks) } & \multirow[t]{2}{*}{ BBW (g) } & \multirow{2}{*}{$\begin{array}{c}\text { Apgar score } 1 \mathrm{~min} / 5 \\
\mathrm{~min}\end{array}$} & \multirow[t]{2}{*}{ Acute phase illness } & \multicolumn{3}{|c|}{ At the day of Kangaroo care } \\
\hline & & & & & & PCA (wks) & BW (g) & Theophylline \\
\hline 1 & M & 28 & 1228 & $8 / 8$ & PPHN & 34 & $|53|$ & Yes \\
\hline 2 & $M$ & 28 & 1258 & $8 / 9$ & TTN & 33 & 1458 & Yes \\
\hline 3 & $\mathrm{~F}$ & 31 & 1282 & $7 / 9$ & RDS & 34 & 1222 & No \\
\hline 4 & $\mathrm{~F}$ & 30 & 1538 & $7 / 8$ & RDS & 34 & 1482 & No \\
\hline 5 & $\mathrm{~F}$ & 30 & 1228 & $7 / 8$ & RDS & 36 & 1298 & No \\
\hline 6 & $\mathrm{~F}$ & 28 & 1140 & $6 / 8$ & TTN & 40 & 1638 & No \\
\hline 7 & $\mathrm{~F}$ & 27 & 1152 & $1 / 6$ & RDS & 36 & 1298 & No \\
\hline 8 & $M$ & 33 & 1586 & $7 / 9$ & TTN & 36 & 1752 & No \\
\hline 9 & $M$ & 24 & 692 & $8 / 8$ & RDS & 40 & 1064 & Yes \\
\hline 10 & $M$ & 25 & 756 & $5 / 7$ & RDS & 35 & 1043 & Yes \\
\hline 11 & $M$ & 27 & 1272 & $2 / 3$ & RDS & 37 & $|58|$ & No \\
\hline 12 & $M$ & 25 & 866 & $5 / 8$ & RDS & 41 & 1858 & No \\
\hline 13 & $\mathrm{~F}$ & 29 & 1106 & $9 / 9$ & RDS & 36 & 1359 & No \\
\hline 14 & $M$ & 26 & 982 & $9 / 10$ & RDS & 36 & 946 & No \\
\hline 15 & $M$ & 25 & 772 & $6 / 6$ & RDS & 42 & 1334 & No \\
\hline 16 & $M$ & 27 & 1130 & $7 / 9$ & CLD & 36 & 1540 & No \\
\hline
\end{tabular}

GA: gestational age, BBW: birth body weight, PCA: postconceptional age, BW: body weight, PPHN: persistent pulmonary hypertension of the newborn, RDS: respiratory distress syndrome, TTN: transient tachypnea of the newborn

percentages of oxygen saturation $\left(\mathrm{SpO}_{2}\right)$. Regional cerebral oxygenation was measured with a near infrared spectroscopy, NIRS (INVOS 4100, Somanetics, Troy, MI), with the two probes positioned on the bilateral frontoparietal areas. Physiological data were recorded at 10 second intervals (averaged over 10 second period) through a Wave Archiving System (WAS-J: Agilent Technologies, Inc.) and further analyzed. Data from the first 30 minutes during $\mathrm{KC}$ were excluded from the analysis to minimize the effects of changes due to the adaptation process. The data for $\mathrm{rSO}_{2}$ were recorded from both the left and right hemispheres independently ( $\mathrm{LrSO}_{2}$ and $\mathrm{RrSO}_{2}$, respectively).

Behavioral states of infants were recorded throughout the observation period using the Brazelton Neonatal Behavior Assessment Scale [30]. Behavioral states of infant were observed by nurses trained on the observational scale. Five different behavioral states were observed: 1) Quiet sleep; 2) Active sleep; 3) Drowsiness; 4) Alert inactivity; and 5) Active awake. Behavioral states were judged before $\mathrm{KC}$, during $\mathrm{KC}$, at the end of $\mathrm{KC}$, and 30 minutes after $\mathrm{KC}$. Body temperature was measured at the beginning of data recording before the $\mathrm{KC}$ session and after the end of $\mathrm{KC}$. Informed consents were obtained from the parents and the study was approved by the ethical committee of the institute.

\section{Power spectral analysis}

Power spectral analysis was performed on $\mathrm{rSO}_{2}, \mathrm{HR}, \mathrm{RR}$, and $\mathrm{SpO}_{2}$ in three sessions as previously reported [28]. The power spectral density was calculated and divided into two frequency bands in each session as shown in Figure 1 . The regional power of low - frequency (LF, $0.02-$ $0.2 \mathrm{~Hz}$ ) and high - frequency ( $\mathrm{HF}, 0.20-0.5 \mathrm{~Hz}$ ) bands, and the ratio of $\mathrm{LF} / \mathrm{HF}$ were calculated. The powers of LF and HF were normalized using the formulas $\% \mathrm{LF}=\mathrm{LF} / \mathrm{TP}$ $\times 100(\%)$ and $\% \mathrm{HF}=\mathrm{HF} / \mathrm{TP} \times 100(\%)$ [31]. Total power (TP) was obtained by integrating the power spectrum from frequency 0.02 to $0.50 \mathrm{~Hz}$.

\section{Statistical analysis}

Data were analyzed with SPSS 13.0 for Windows (SPSS Inc., Chicago, IL). A repeated measures ANOVA was performed to analyze the differences of parameters among three sessions. Conventional statistics: mean, standard deviation, coefficient of variance (CV), range, normal distribution, and median were performed for all parameters. Data are expressed as median (range) or mean \pm SD.

\section{Results \\ Descriptive statistical analysis}

Descriptive statistics of $\mathrm{HR}, \mathrm{RR}, \mathrm{SpO}_{2}, \mathrm{LrSO}_{2}$ and $\mathrm{RrSO}_{2}$ are shown in Table 2. In mean $\mathrm{HR}_{1}, \mathrm{SpO}_{2}, \mathrm{LrSO}_{2}$, and $\mathrm{RrSO}_{2}$, there were no significant differences among the three sessions; however, RR was significantly increased during $\mathrm{KC}$ and decreased after $\mathrm{KC}$ ( $\mathrm{p}<0.05$, respectively). Body temperature was increased by $0.3^{\circ} \mathrm{C}$ during $\mathrm{KC}(\mathrm{p}<$ $0.01)$. The CV of HR was decreased by $2.2 \%$ during $\mathrm{KC}(\mathrm{p}$ $<0.05$ ), while it was increased again after KC by $2.9 \%$ (p $<0.05)$. There were no significant differences in the CVs of $\mathrm{RR}, \mathrm{SpO}_{2}, \mathrm{LrSO}_{2}$, and $\mathrm{RrSO}_{2}$. 


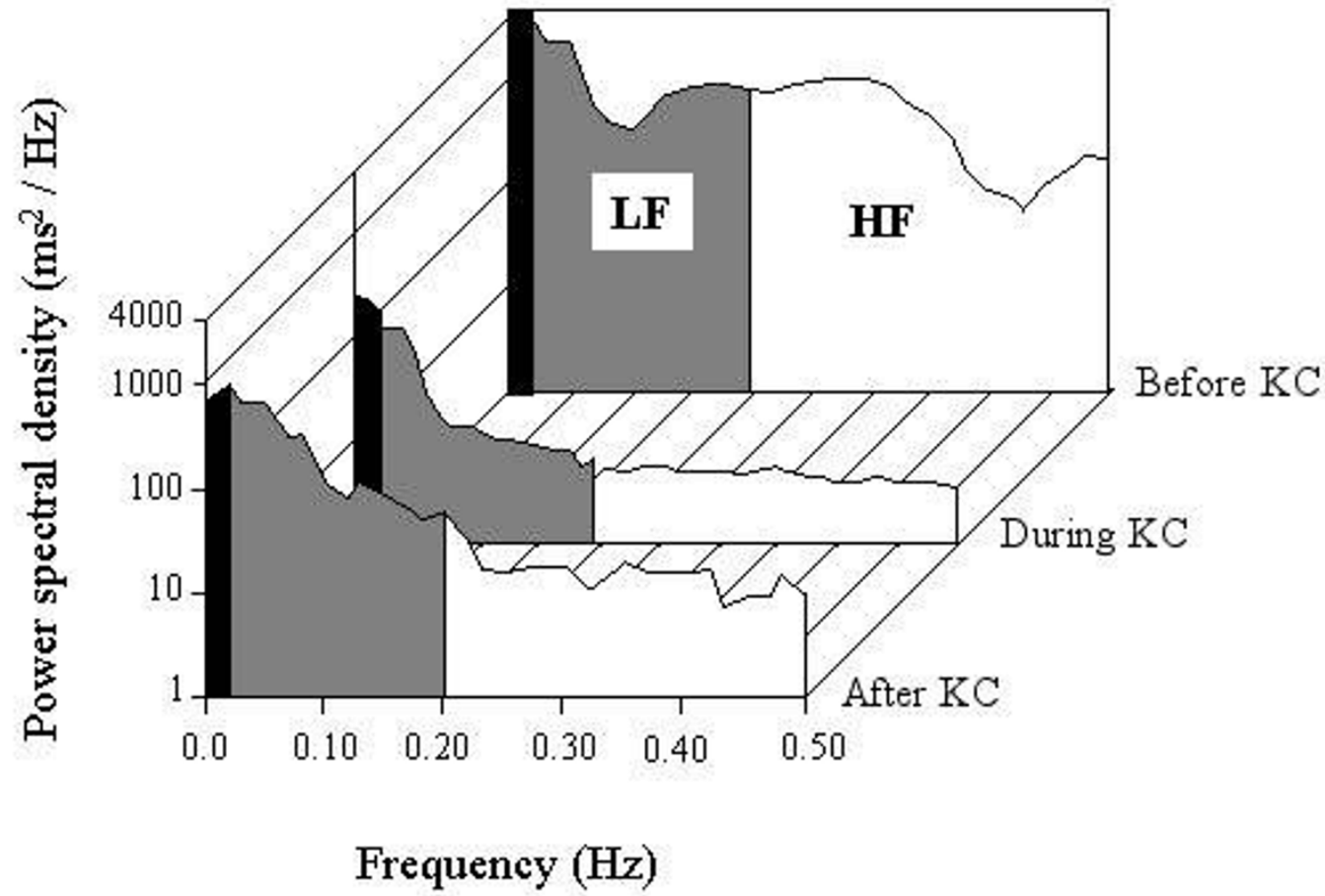

\section{Figure I}

A typical graph of power spectral density $\left(\mathrm{ms}^{2} / \mathrm{Hz}\right)$ of right $\mathrm{rSO}_{2}$ displaying the power of the low frequency (LF: $0.02-0.2 \mathrm{~Hz}$ ) and high frequency (HF: $0.2-0.5 \mathrm{~Hz}$ ) bands before, during, and after the KC session.

\section{Power spectral analysis}

Changes in TP during the sessions were shown in Figure 2. The TP of HR was significantly decreased during KC and increased after KC (before: $635 \pm 280$, during: $268 \pm 134$, after: $618 \pm 240 \mathrm{~ms}^{2} / \mathrm{Hz}$; before vs during and during vs after, $\mathrm{p}<0.01)$. The TP of $\mathrm{SpO}_{2}$ had a similar tendency to that of HR. On the other hand, the TP of RR was significantly increased during $\mathrm{KC}$ and decreased after $\mathrm{KC}$ (before: $458 \pm 186$, during: $713 \pm 175$, after: $461 \pm 231$ $\mathrm{ms}^{2} / \mathrm{Hz}$; before vs during and during vs after, $\left.\mathrm{p}<0.01\right)$. In regional cerebral oxygenation, the TP of either $\mathrm{LrSO}_{2}$ or $\mathrm{RrSO}_{2}$ was significantly decreased during $\mathrm{KC}$ and increased again after $\mathrm{KC}\left(\mathrm{LrSO}_{2}\right.$ : before: $121 \pm 91$, during: $54 \pm 41$, after: $90 \pm 56 \mathrm{~ms}^{2} / \mathrm{Hz} ; \mathrm{RrSO}_{2}$ : before: $123 \pm 69$, during: $55 \pm 30$, after: $98 \pm 46 \mathrm{~ms}^{2} / \mathrm{Hz}$; before vs during and during vs after, $\mathrm{p}<0.001$, respectively in each parameter).

The percentages of $\mathrm{LF}, \mathrm{HF}$, and the ratio of $\mathrm{LF} / \mathrm{HF}$ are shown in Figure 3A and 3B. For HR, the \%LF was significantly increased during KC (before: $41.4 \pm 11.5$, during: $48.3 \pm 9.8 \%, \mathrm{p}<0.05$ ), while $\% \mathrm{HF}$ was decreased (before: $45.9 \pm 13.9$, during: $33.5 \pm 15.3 \%$ ). In contrast, the \%LF of $\mathrm{rSO}_{2}$ was significantly decreased during $\mathrm{KC}$ for both $\mathrm{LrSO}_{2}$ (before: $63.5 \pm 11.2$, during: $49.2 \pm 9.2$, after: 63.8 $\pm 10.2 \%$; before vs during and during vs after, $\mathrm{p}<0.01$ ) and $\mathrm{RrSO}_{2}$ (before: $59.1 \pm 11.5$ during: $49.9 \pm 6.9$, after: $57.0 \pm 13.6 \%$; before vs during, $\mathrm{p}<0.05)$. The $\% \mathrm{HF}$ was decreased during $\mathrm{KC}$ for $\mathrm{RrSO}_{2}$ (before: $28.1 \pm 13.8$, during: $22.6 \pm 10.9$, after: $26.2 \pm 19.2 \%$; before vs during, $\mathrm{p}<$ $0.01)$, although there was no significant change in this parameter for $\mathrm{LrSO}_{2}$ during the sessions. For RR and $\mathrm{SpO}_{2}$, significant changes were not observed in \%LF or HF during $\mathrm{KC}$, although the \%LF of RR after $\mathrm{KC}$ was significantly increased while the $\% \mathrm{HF}$ was decreased $(\mathrm{p}<0.05$, respectively) with an increased $\mathrm{LF} / \mathrm{HF}$ ratio $(\mathrm{p}<0.01)$. There were no significant differences in the ratio of $\mathrm{HR}, \mathrm{SpO}_{2}$, $\mathrm{LrSO}_{2}$, and $\mathrm{RrSO}_{2}$ during the sessions (Figure 3B).

At the day of $\mathrm{KC}$, four infants had received theophylline. Infants who received theophylline showed the similar tendency to those without theophylline during $\mathrm{KC}$ and after KC.

\section{Behavioral analysis}

The behavioral states during the observation period are shown in Figure 4. The percentage of infants with quiet sleep states remarkably increased during KC (61.5\%) compared to those before $\mathrm{KC}(15.4 \%)$. This percentage increased further to $76.9 \%$ at the end of $\mathrm{KC}$ and decreased to $38.5 \%$ at 30 minutes after $\mathrm{KC}$. In contrast, the percentage of infants in active sleep was $53.8 \%$ before $\mathrm{KC}$, 
Table 2: Central tendencies and coefficient of variances of physiological variables before, during and after KC intervention

\begin{tabular}{|c|c|c|c|c|}
\hline Variables & Measures & Before KC & During KC & After KC \\
\hline \multirow[t]{2}{*}{ Heart rate $(\mathrm{bpm})$} & Mean & $149.4 \pm 6.3$ & $150.0 \pm 10.0$ & $150.4 \pm 8.7$ \\
\hline & $\mathrm{CV}$ & $6.8 \pm 3.2$ & $4.6 \pm 1.3^{*}$ & $7.5 \pm 4.7 \dagger$ \\
\hline \multirow[t]{2}{*}{ Respiratory rate (bpm) } & Mean & $39.4 \pm 8.9$ & $44.0 \pm 5.1^{* *}$ & $39.7 \pm 7.9+\dagger$ \\
\hline & $\mathrm{CV}$ & $24.1 \pm 5.4$ & $22 \pm 6.7$ & $19.7 \pm 7.6$ \\
\hline \multirow[t]{2}{*}{$\mathrm{SpO}_{2}(\%)$} & Mean & $98.0 \pm 1.3$ & $97.6 \pm 2.5$ & $97.5 \pm 1.7$ \\
\hline & $\mathrm{CV}$ & $2.3 \pm 1.4$ & $1.5 \pm 0.9$ & $2.9 \pm 2.4$ \\
\hline \multirow[t]{2}{*}{ Left-rSO ${ }_{2}(\%)$} & Mean & $46.8 \pm 5.6$ & $47.3 \pm 6.1$ & $47.5 \pm 7.3$ \\
\hline & $\mathrm{CV}$ & $6.6 \pm 4.1$ & $5.8 \pm 3.3$ & $4.1 \pm 1.6$ \\
\hline \multirow[t]{2}{*}{ Right-r $\mathrm{SO}_{2}(\%)$} & Mean & $48.6 \pm 6.9$ & $49.1 \pm 9.4$ & $47.8 \pm 6.9$ \\
\hline & $\mathrm{CV}$ & $7.2 \pm 4.6$ & $7.2 \pm 5.5$ & $5.6 \pm 2.3$ \\
\hline \multirow[t]{2}{*}{ Body temperature, $\left({ }^{\circ} \mathrm{C}\right)$} & Mean & $37.0 \pm 0.2^{* * * *}$ & $37.3 \pm 0.3$ & \\
\hline & Median (range) & $37.1(36.6-37.4)$ & $37.3(36.8-37.4)$ & \\
\hline
\end{tabular}

Data were expressed as mean \pm SD or median (range). ${ }^{*} \mathrm{p}<0.05$, ${ }^{* *} \mathrm{p}<0.0 \mathrm{I}$, ${ }^{* * *} \mathrm{p}<0.00 \mathrm{I}$, before versus during $\mathrm{KC}$ and $\dagger \mathrm{p}<0.05, \dagger \dagger \mathrm{p}<0.0 \mathrm{I}$, during versus after $\mathrm{KC}$. $\mathrm{CV}$ : coefficient of variance, $\mathrm{rSO}_{2}$ : regional cerebral oxygenation.

decreased to $23.1 \%$ in the middle of $\mathrm{KC}$, and increased to $54.0 \%$ at 30 minutes after KC.

\section{Discussion}

In this study, regional cerebral oxygenation using NIRS was measured during $\mathrm{KC}$ in addition to cardiorespiratory parameters in stable low birth weight infants and analyzed by using power spectral analysis. By conventional analysis, the CV of HR was decreased, and mean RR and body temperature were increased during $\mathrm{KC}$ as previously reported $[7,9,14]$; however, significant changes were not found in mean $\mathrm{rSO}_{2}$. By power spectral analysis, TP was decreased in $\mathrm{rSO}_{2} ; \mathrm{HR}$, and $\mathrm{SpO}_{2}$ during $\mathrm{KC}$, whereas the $\mathrm{TP}$ of RR was increased. Further, the $\mathrm{LF}$ of $\mathrm{rSO}_{2}$ was found to be decreased during $\mathrm{KC}$ while the $\mathrm{LF}$ of $\mathrm{HR}$ was increased with decreased HF. This study has shown that the spectral characteristics of cerebral oxygenation are significantly different between during $\mathrm{KC}$ and before $\mathrm{KC}$ or after $\mathrm{KC}$ as well as $\mathrm{HR}, \mathrm{RR}$ and $\mathrm{SpO}_{2}$; however, there were no significance differences in their mean values. The power spectral analysis was found as a more effective analytic approach for revealing the physiological responses compared to the conventional analysis.

In spectral analysis of heart rate variability (HRV), low frequencies $(0.02-0.20 \mathrm{~Hz})$ reflect sympathetic activities such as the baroreceptor reflex, high-frequencies (0.2 $2.0 \mathrm{~Hz}$ ) reflect parasympathetic activities such as vagal activity, and the ratio of LF/HF power reflects the balance between sympathetic and parasympathetic activities [2326,32]. Several studies have been published on autonomic function of HRV in preterm infants and only two studies had been previously reported on HRV during KC intervention using power spectral analysis up to now. One of them showed a decrease of LF and HF during KC [27], while the other showed an increase of LF during KC [28]. In our study, the LF of HR was increased during $\mathrm{KC}$ and the $\mathrm{LF}$ of $\mathrm{rSO}_{2}$ was decreased. In general, the increase in sympathetic activities and decrease in cerebral oxygen delivery with the head in an up-tilting position are assumed to be due to gravity causing pooling of blood and thereby activating baroreceptors as previously reported [29,33], and the decrease of $\mathrm{LF}$ of $\mathrm{rSO}_{2}$ during $\mathrm{KC}$ with increased LF of HR described in this study might be supported previous studies. These results could be understood as activation of the central nervous system and brain function during $\mathrm{KC}$ position. Besides these, the increase in body temperature and respiration observed in our study may have an effect on the LF of HR as previously reported on HRV [28,34]. Further, TP is the index of total variance in power spectral analysis and changes in TP during $\mathrm{KC}$ indicate the changes in total variance. In our study, $\mathrm{TP}$ of $\mathrm{rSO}_{2}, \mathrm{HR}$, or $\mathrm{SpO}_{2}$ have been shown to decrease during KC. A possible explanation for these decreases during KC might be associated with reduced activity and increased quiet sleep state during $\mathrm{KC}$ as previously reported [35,36]. These results could be interpreted as physiological stability elicited by $\mathrm{KC}$ intervention. Although the dominance of HF has been reported in HR during the quiet sleep state $[37,38]$, this was not observed during KC in a previous study [28] or in the current study. The position of the head of infants during KC might be responsible for the discrepancy between the left and right $\mathrm{rSO}_{2}$.

To our knowledge, the present study was the first study to analyze the response of $\mathrm{rSO}_{2}$ due to $\mathrm{KC}$ in $\mathrm{LBW}$ preterm infants through spectral characteristics. Therefore, it was difficult to compare the results of this study with other similar studies and apply to the clinical settings. Despite the sampling limitation, this reference data provide new understanding into the response of cerebral hemodynamics in preterm infants and should have significant implications to generalize the $\mathrm{rSO}_{2}$ responses with different modalities in LBW infants. Further studies are necessary to determine the clinical relevance of the present findings. 


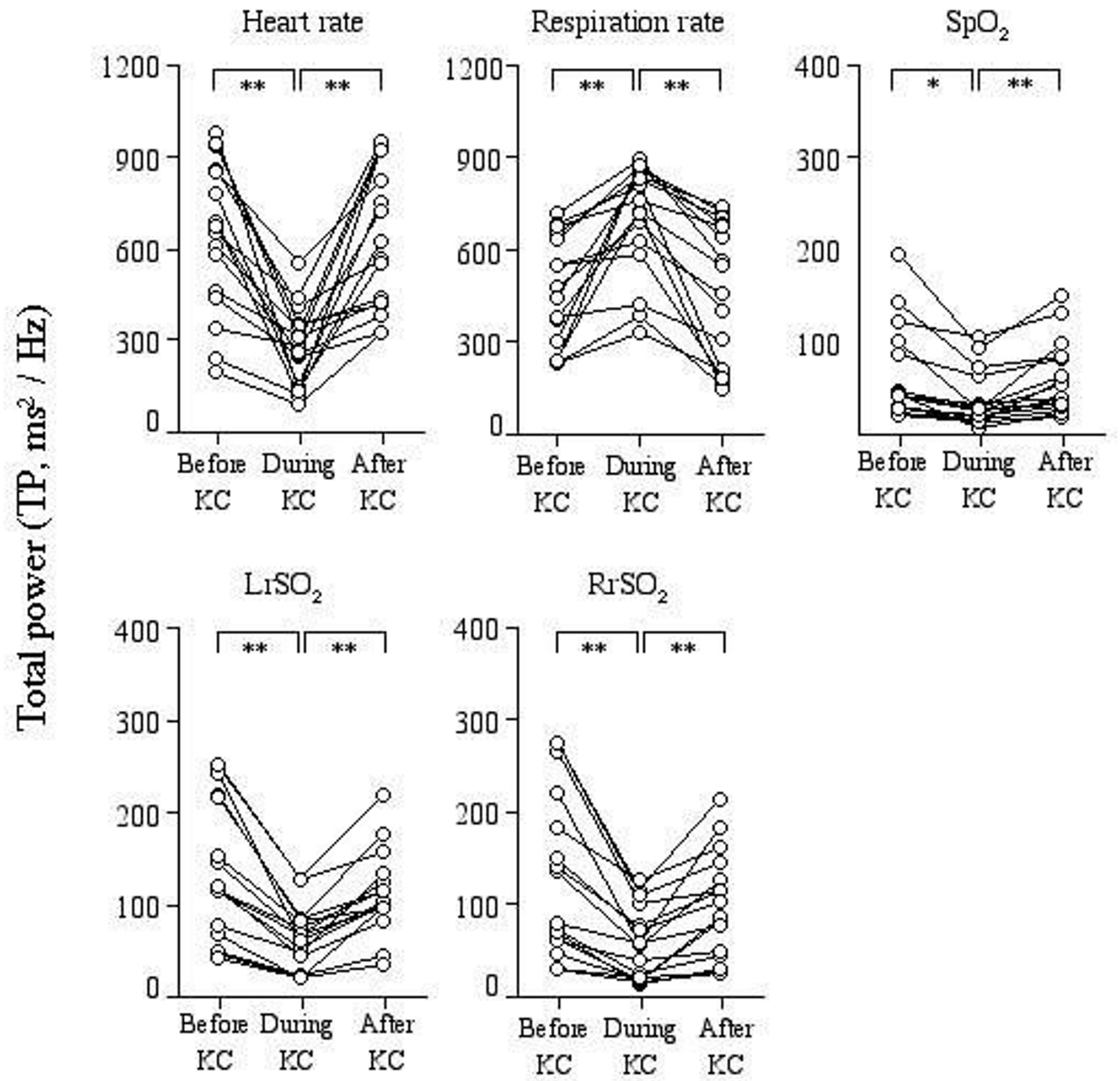

Figure 2

Individual values of total power (TP) of power spectral density before, during, and after KC, displaying visually qualitative changes during KC. A repeated measures ANOVA was performed to determine the statistical differences among the three sessions: before, during, and after $K C .{ }^{*} \mathrm{p}<0.0 \mathrm{I}$, ${ }^{*} \mathrm{p}<0.00 \mathrm{I}$, before vs during $\mathrm{KC}$ or during vs after $\mathrm{KC}$.

\section{Conclusion}

The results of this study revealed that changes of cerebral hemodynamics associated with $\mathrm{KC}$ position in preterm infants as well as cardiorespiratory parameters. These changes were especially apparent by power spectral analysis. Furthermore, the results of this study indicate that $\mathrm{KC}$ may contribute to the activation of central nervous system and brain function. Further study is needed to determine the underlying physiology responsible for these differences. 

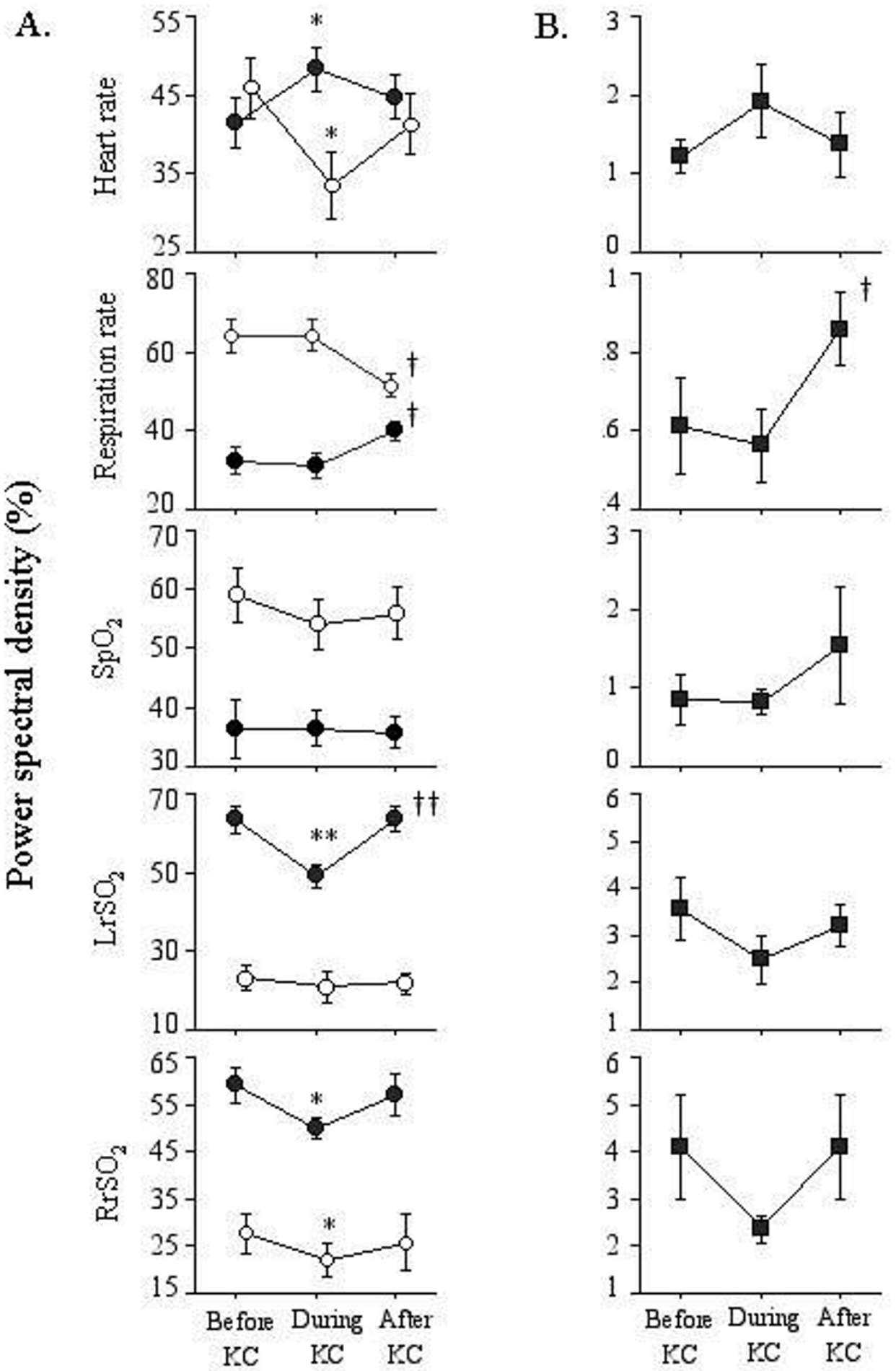

Figure 3

A: Power spectral density in low - frequency (LF: close circle) and high - frequency (HF: open circle) bands before, during, and after KC. LF and HF are expressed as normalized values (\%LF = LF/total power $\times 100$ and \%HF $=\mathrm{HF} /$ total power $\times 100)$. B. The ratio of LF/HF before, during, and after KC. Data is presented as means \pm SEM. A repeated measures ANOVA was performed to determine the statistical differences among the three sessions: before, during, and after KC. * $\mathrm{p}<0.05$, ** $\mathrm{p}<0.0 \mathrm{I}$, before vs during KC. $\dagger \mathrm{p}<0.05, \dagger+\mathrm{P}<0.0 \mathrm{I}$, during vs after $\mathrm{KC}$. 


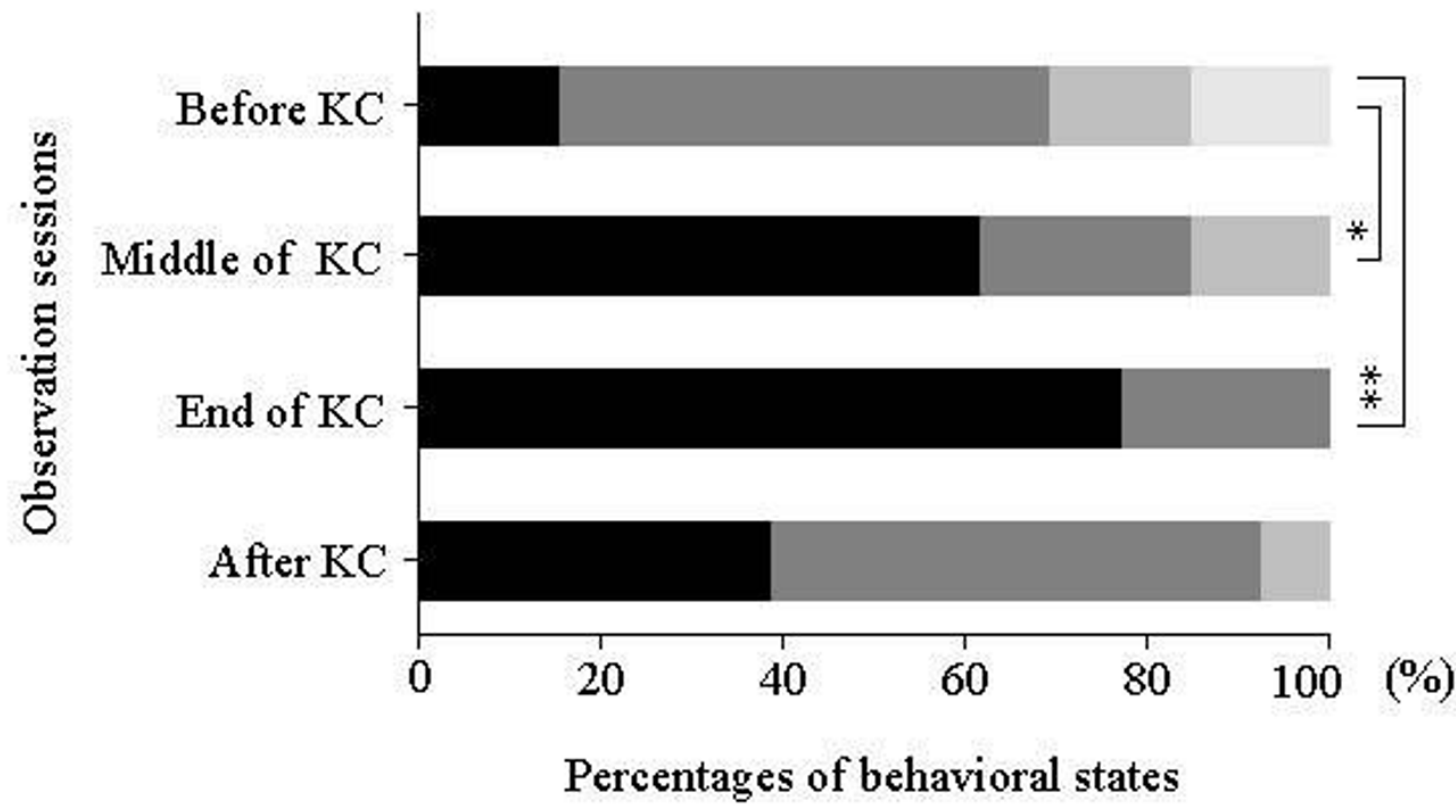

Quiet sleep

Active sleep

\section{Drowsiness}

\section{Active Awake Alert inactivity}

Figure 4

Behavioral states of infants observed before $K C$, in the middle of $K C$, at the end of $K C$, and 30 minutes after KC. The quiet sleep state was remarkably increased in the middle of $K C$ and at the end of $K C$. A chi square test was performed to determine the significant differences in the four behavioral states. ${ }^{*} \mathrm{p}<0.05$, ${ }^{* *} \mathrm{p}<0.0 \mathrm{I}$, before versus middle of $\mathrm{KC}$ or before versus end of $\mathrm{KC}$.

\section{Abbreviations}

KC: Kangaroo care; LBW: low birth weight; NICU: neonatal intensive care unit; FFT: fast Fourier transformation; $\mathrm{LrSO}_{2}$ : left side regional cerebral oxygenation; $\mathrm{RrSO}_{2}$ : right side regional cerebral oxygenation; HR: heart rate, RR: respiration rate; TP: total power; HF: high frequency; LF: low frequency; weeks, wks; NIRS: near infrared spectroscopy, ECG: electrocardiogram, HRV, heart rate variability.

\section{Competing interests}

The authors declare that they have no competing interests.

\section{Authors' contributions}

EAB: Participated in all data collection, in the analysis and discussion of the results, and in the writing of the manuscript; MB: Mainly worked with first author and responsible for this study.; NO: Participated in all clinical and physiological data collection; SY: Participated in organized the study group with nursing staff.; ST: Participated in interpretation of clinical findings and theoretical support;
HY: Introduced and established the NICU local area network system (LAN system) for physiological data recording and Participated in clinical suggestion about physiological rhythmicity; MK: Participated in theoretical support of physiological instability in neonates and physiological rhythmicity; YK: Organized the study group and checked the manuscript finally.

\section{Acknowledgements}

The funding of this study was supported in part by National Hospital Organization (NHO). We thank the staff of the Department of Nursing for their assistance in the data collection in the NICU.

\section{References}

I. Whitelaw A, Sleath K: Myth of the marsupial mother: home care of very low birth weight babies in Bogota, Colombia. Lancet 1985, I: | 206-1208.

2. Anderson GC: Current knowledge about skin-to-skin (kangaroo) care for preterm infants. J Perinatol |99|, I I:2 |6-226.

3. Ludington-Hoe SM, Swinth JY: Developmental aspects of kangaroo care. J Obstet Gynecol Neonatal Nurs 1996, 25:69I-703.

4. Dodd VL: Implications of kangaroo care for growth and development in preterm infants. J Obstet Gynecol Neonatal Nurs 2005, 34:218-232. 
5. Tessier R, Cristo M, Velez S, Giron M, de Calume ZF, Ruiz-Palaez JG et al: Kangaroo mother care and the bonding hypothesis. Pediatrics 1998, 102:el7.

6. Mondlane RPdGAMP, Ebrahim G]: Skin-to-Skin Contact as a Method of Body Warmth for Infants of Low Birth Weight. J Trop Pediatr 1989, 35:32I-326.

7. Bauer K, Uhrig C, Sperling P, Pasel K, Wieland C, Versmold HT: Body temperatures and oxygen consumption during skin-toskin (kangaroo) care in stable preterm infants weighing less than 1500 grams. J Pediatr 1997, I 30:240-244.

8. Ludington-Hoe SM, Nguyen N, Swinth JY, Satyshur RD: Kangaroo care compared to incubators in maintaining body warmth in preterm infants. Biol Res Nurs 2000, 2:60-73.

9. Ludington-Hoe SM, Anderson GC, Simpson S, Hollingsead A, Argote LA, Rey $\mathrm{H}$ : Birth-related fatigue in 34-36-week preterm neonates: rapid recovery with very early kangaroo (skin-toskin) care. J Obstet Gynecol Neonatal Nurs 1999, 28:94-103.

10. Fohe K, Kropf S, Avenarius S: Skin-to-skin contact improves gas exchange in premature infants. J Perinatol 2000, 20:3 II-315.

II. Acolet $D$, Sleath $K$, Whitelaw $A$ : Oxygenation, heart rate and temperature in very low birthweight infants during skin-toskin contact with their mothers. Acta Paediatr Scand 1989, 78: $189-193$

12. Cattaneo ADR, Bergman N, Charpak N: Kangaroo mother care in low-income countries. International network in Kangaroo Mother Care. J Trop Pediatr 1998, 44:279-282.

13. Feldman R, Eidelman Al: Skin-to-skin contact (Kangaroo Care) accelerates autonomic and neurobehavioural maturation in preterm infants. Dev Med Child Neurol 2003, 45:274-28I.

14. Messmer PR, Rodriguez S, Adams J, Wells-Gentry J, Washburn K, Zabaleta I, Abreu S: Effect of kangaroo care on sleep time for neonates. Pediatr Nurs 1997, 23:408-4I4.

15. Ludington SM: Energy conservation during skin-to-skin contact between premature infants and their mothers. Heart Lung 1990, 19:445-45।.

16. Bohnhorst B, Heyne T, Peter CS, Poets CF: Skin-to-skin (kangaroo) care, respiratory control, and thermoregulation. J Pediatr 2001, 138:193-197.

17. Smith SL: Physiologic Stability of Intubated VLBW Infants During Skin-to-Skin Care and Incubator Care. Advances in Neonatal care 200 I, I:28-40.

18. Volpe J]: Hypoxic-ischemic encephalopathy. In Neurology of the newborn Edited by: Volpe JJ. Philadelphia, Saunders; 200I:296-330.

19. Toet MC, Lemmers PM, van Schelven LJ, van Bel F: Cerebral oxygenation and electrical activity after birth asphyxia: their relation to outcome. Pediatrics 2006, I I 7:333-339.

20. Meek JH, Elwell CE, McCormick DC, Edwards AD, Townsend JP, Stewart AL, Wyatt JS: Abnormal cerebral haemodynamics in perinatally asphyxiated neonates related to outcome. Arch Dis Child Fetal Neonatal Ed 1999, 81:FI I0-II5.

21. van Bel F, Dorrepaal CA, Benders MJ, Zeeuwe PE, Bor M van de, Berger HM: Changes in cerebral hemodynamics and oxygenation in the first $\mathbf{2 4}$ hours after birth asphyxia. Pediatrics 1993, 92:365-372.

22. Munger DM, Bucher HU, Duc G: Sleep state changes associated with cerebral blood volume changes in healthy term newborn infants. Early Hum Dev 1998, 52:27-42.

23. Patural H, Pichot V, Jaziri F, Teyssier G, Gaspoz JM, Roche F, Barthelemy JC: Autonomic cardiac control of very preterm newborns: A prolonged dysfunction. Early Hum Dev 2008.

24. De Rogalski Landrot I, Roche F, Pichot V, Teyssier G, Gaspoz JM, Barthelemy JC, Patural $\mathrm{H}$ : Autonomic nervous system activity in premature and full-term infants from theoretical term to 7 years. Auton Neurosci 2007, 136: 105-109.

25. Nakamura T, Horio H, Miyashita S, Chiba Y, Sato S: Identification of development and autonomic nerve activity from heart rate variability in preterm infants. Biosystems 2005, 79: I I7-124.

26. Andriessen P, Oetomo SB, Peters C, Vermeulen B, Wijn PF, Blanco $C E$ : Baroreceptor reflex sensitivity in human neonates: the effect of postmenstrual age. J Physiol 2005, 568:333-34I.

27. McCain GC, Ludington-Hoe SM, Swinth JY, Hadeed AJ: Heart rate variability responses of a preterm infant to kangaroo care. J Obstet Gynecol Neonatal Nurs 2005, 34:689-694.

28. Smith SL: Heart period variability of intubated very-low-birthweight infants during incubator care and maternal holding. Am J Crit Care 2003, I 2:54-64.
29. Tachtsidis I, Elwell CE, Lee CW, Leung TS, Smith M, Delpy DT: Spectral characteristics of spontaneous oscillations in cerebral haemodynamics are posture dependent. Adv Exp Med Biol 2003, 540:31-36

30. Brazelton TB: Neonatal Behavioral Assessment Scale 2nd edition. London: Heinemann; 1984.

31. Andriessen P, Koolen AM, Berendsen RC, Wijn PF, ten Broeke ED Oei SG, Blanco CE: Cardiovascular fluctuations and transfer function analysis in stable preterm infants. Pediatr Res 2003 , 53:89-97.

32. Smith SL, Doig AK, Dudley WN: Characteristics of heart period variability in intubated very low birth weight infants with respiratory disease. Biol Neonate 2004, 86:269-274.

33. Schord L, Walter J: Effect of head-up body tilt position on autonomic function and cerebral oxygenation in preterm infants. Biology of the Neonate 2002, 81:255-259.

34. Davidson S, Reina N, Shefi O, Hai-Tov U, Akselrod S: Spectral analysis of heart rate fluctuations and optimum thermal management for low birth weight infants. Med Biol Eng Comput 1997, 35:619-625.

35. Ludington-Hoe SM, Thompson C, Swinth J, Hadeed AJ, Anderson GC: Kangaroo care: research results, and practice implications and guidelines. Neonatal Netw 1994, 13:19-27.

36. Porges SW, McCabe PM, Yongue BG: Respiratory-heart rate interaction and psycho-physiological implications for pathophysiology and behavior. Cacioppor JT, Petty R, editors. Perspectives in Cardiovascular Psychophysiology. New York Guilford Press; 1982.

37. Porges SW, Doussard-Roosevelt JA, Stifter CA, McClenny BD, Riniolo TC: Sleep state and vagal regulation of heart period patterns in the human newborn: an extension of the polyvagal theory. Psychophysiology 1999, 36:14-2I.

38. Villa MP, Calcagnini G, Pagani J, Paggi B, Massa F, Ronchetti R: Effects of sleep stage and age on short-term heart rate variability during sleep in healthy infants and children. Chest 2000, I 1 7:460-466.

\section{Pre-publication history}

The pre-publication history for this paper can be accessed here:

http://www.biomedcentral.com/1471-2431/8/51/prepub
Publish with Bio Med Central and every scientist can read your work free of charge

"BioMed Central will be the most significant development for disseminating the results of biomedical research in our lifetime. "

Sir Paul Nurse, Cancer Research UK

Your research papers will be:

- available free of charge to the entire biomedical community

- peer reviewed and published immediately upon acceptance

- cited in PubMed and archived on PubMed Central

- yours - you keep the copyright
BioMedcentral 